\title{
EDUCAÇÃO FÍSICA ESCOLAR NO ENSINO MÉDIO: O USO DAS REDES SOCIAS NOS PROCESSOS DE ENSINO-APRENDIZAGEM A PARTIR DA PERSPECTIVA DE AULAS ABERTAS
}

\author{
Thiago Sousa Matias \\ Universidade Federal de Santa Catarina, Florianópolis, Santa Catarina, Brasil. \\ Muryllo Rezende Soares \\ Universidade do Vale do Itajaí, Itajaí, Santa Catarina, Brasil. \\ Otto Silva \\ Universidade do Vale do Itajaí, Itajaí, Santa Catarina, Brasil. \\ Jéssica Serafim Frasson \\ Universidade Federal do Rio Grande do Sul, Porto Alegre, Rio Grande do Sul, Brasil. \\ Veruska Pires \\ Universidade Federal do Rio Grande do Sul, Porto Alegre, Rio Grande do Sul, Brasil.
}

\begin{abstract}
Resumo
Este trabalho buscou investigar o potencial inovador e educacional na disciplina de Educação Física através da diversificação do conteúdo, redes sociais e aulas abertas. A proposta foi desenvolvida na disciplina de estágio supervisionado no ensino médio, e realizada em uma escola pública mantida pelo estado de Santa Catarina. As análises foram sistematizadas nas redes sociais e foram feitos relatórios de observação com interpretação temática e categorial. As redes sociais promovem espaço de discussão, são úteis para a realização de tarefas, permitem avaliação e auxiliam na preservação e significação do conteúdo. A diversidade dos conteúdos motiva os alunos, elimina a evasão e impulsiona discussões educacionais. As aulas abertas geram reflexões, motivação, ação comunicativa e autonomia.
\end{abstract}

Palavras-chave: Educação. Difusão de Inovações. Rede Social.

\section{PHYSICAL EDUCATION IN HIGH SCHOOL: THE USE OF SOCIAL NETWORK- ING AS A STRATEGY TO IMPROVE LEARNING IN AN OPEN CLASSES PER- SPECTIVE}

\begin{abstract}
Based on diversification of content, social networking and open classes, this study aimed to investigate the innovative and educational potential in Physical Education (PE). The study was conducted through supervised stage in high school. Analyzes were systematized in social networks and observation reports and categorical interpretation was used. Social network promotes more discussion and it is useful to perform PE tasks. Also allows evaluation and assists in the preservation and significance of content. The diversity of content motivates students, eliminates evasion and boost educational discussions. Open classes increase reflection, motivation, communication and autonomy.
\end{abstract}

Keywords: Education. Diffusion of Innovation. Social Network. 


\title{
EDUCACIÓN FÍSICA ESCOLAR: EL USO DE LAS REDES SOCIALES EN LOS PROCESOS DE ENSEÑANZA-APRENDIZAJE A PARTIR DE LA PERSPECTIVA DE CLASES ABIERTAS
}

\begin{abstract}
Resumen
Este trabajo tiene el objetivo de investigar el potencial innovador y educativo en la Educación Física, a través de la diversificación del contenido en las redes sociales y clases abiertas. La propuesta se desarrolló en la asignatura pasantía supervisada en la enseñanza secundaria y fue desarrollada en una escuela pública del Estado de Santa Catarina. Los análisis fueron sistematizados en las redes sociales y los informes de observación con interpretación temática y categorial. Las redes sociales suscitan espacios de discusión, son útiles para la realización de tareas, permiten la evaluación y ayuda en la preservación y significado del contenido. La diversidad de los contenidos estimula a los alumnos, elimina la evasión e impulsa discusiones educativas. Las clases abiertas generan reflexiones, motivación y acción comunicativa y autónoma.

Palabras clave: Educación. Difusión de Innovaciones. Redes Sociales.
\end{abstract}

\section{Introdução}

As aulas de Educação Física (EF) atualmente têm apresentado propostas metodológicas questionáveis quanto ao potencial de inovação (ANDRADE, 2013). É quase discurso comum que a EF como componente curricular não é capaz de ensinar ou atribuir significado aos conteúdos apresentados aos alunos, principalmente os do Ensino Médio (EM) (GARIGLIO, 2015).

Ao longo das últimas três décadas muitas foram as propostas pedagógicas em EF, todas com o intuito de transformar uma realidade historicamente construída com pressupostos tradicionais e com conteúdos ligados aos esportes. Neste movimento, Daolio (2003) destaca proposições que estão subsidiadas na concepção de cultura e que se propõem a compreender a EF a partir de um rigor científico. O autor indica o mérito de autores como Go Tani, Freire, Coletivo de Autores, Kunz, Bracht e Betti na busca de uma ressignificação de suas práticas e concepções. Apesar disso, o que se percebe ainda hoje no EM é uma forte inclinação ao trabalho com os mesmos esportes e, principalmente, a mesma metodologia de ensino desenvolvida desde o ensino fundamental (BRASIL, 2000; DARIDO, 2003; FERREIRA; GRAEBNER; MATIAS, 2014).

Esta mesmice tem imposto aos alunos do EM algumas problemáticas, a EF parece não possuir significado na vida dos adolescentes, ainda é negada a estes alunos a possibilidade de uma reflexão ampliada e diversificada dos conteúdos pertencentes ao escopo da EF. Em estudo com alunos do EM, Brandolin, Koslinski e Soares (2015) reconhecem esta situação ao verificar que a visão positiva sobre a EF escolar: "seja mais influenciada pela possibilidade de ruptura com o tempo ordinário da sala de aula do que com as possibilidades de aprendizagem e satisfação intrínsecas a aquisição de novas habilidades no espaço da educação física" (p. 608).

Emerge desta problemática, dois problemas flagrantes: 1) a desvalorização da EF como disciplina e função educacional e; 2) uma disciplina que não é capaz de justificar sua ação educacional. Percebe-se que a primazia pela ação impossibilitou que os conteúdos se tornassem interessantes para os alunos. Ao repetir as mesmas metodologias de ensino e os conteúdos, somos levados a uma prática motivada pelo simples ativismo, carente e oposta aos fundamentos teóricos (FREIRE, 1987). 
Como forma de mudança e inovação deste processo, as concepções de ensino atuais privilegiam uma relação dialética entre teoria/prática e atentam para os aspectos da modernidade que atendem aos anseios dos jovens. Neste sentido, a partir de um olhar investigativo, este trabalho analisou as potencialidades inovadoras de uma vivência na ação pedagógica em aulas de EF no EM, em que se utilizou da concepção de aulas abertas e das redes sociais como processo metodológico de ensino.

Como facilitador do processo de ensino e aprendizagem optou-se pela possibilidade de definição dos conteúdos a partir dos anseios dos alunos e da utilização das redes sociais na mediação das atividades. Esta escolha buscou quebrar com uma realidade do período da adolescência, em que muitas vezes não há efetiva apropriação das diferentes manifestações da cultura corporal. Fato intensificado em tempos de computadores e smartphones, em que o movimentar-se pode ser suprimido pela sedução e acomodação tecnológica, afastando os alunos da prática. Tal fato, além de afastar da experiência do movimento, ressignifica as práticas corporais (BETTI, 2009a).

A incorporação da internet, através das redes sociais, ao ensino da EF traz vantagens como conhecimento e reflexão: (1) motiva o debate e a reflexão por tratar de assuntos atuais que, em geral, os alunos possuem informações; (2) a linguagem jornalística é atraente para os alunos, visto que é mais sintética e conjugada com imagens e recursos gráficos; (3) as produções audiovisuais conseguem dar destaque e importância para informações, possibilitando uma interpretação mais racionalizada e crítica (BETTI, 2009b). Estas características são atraentes e mais significativas para a incorporação de conceitos e de novas aprendizagens no público do EM.

Diante desta realidade, as experiências didático-pedagógicas foram baseadas na concepção de Aulas Abertas (HILDEBRANDT; LAGING, 1986). Para os autores, as aulas possuem essa característica quando "os alunos participam das decisões em relação aos objetivos, conteúdos e âmbitos de transmissão ou dentro deste complexo de decisão. [...] As possibilidades de decisão dos alunos são determinadas cada vez mais pela decisão previa do professor" (HILDEBRANDT; LAGING, 1986, p. 15).

Nesta proposta, a relação entre professor e aluno é construída e problematizada em conjunto. A autonomia é condição inexorável e há abertura no processo comunicativo, tornando horizontais as ações e decisões pedagógicas. A ideia é promover a capacidade crítica e reflexiva, interesse pela pesquisa e ações proativas. Esse tipo de atividade pedagógica reduz a descrença do aluno na capacidade de suas realizações. A partir de uma concepção aberta os alunos passam a se sentir responsáveis pelo processo de construção do conhecimento (HILDEBRANDT; LAGING, 1986).

\section{Decisões metodológicas}

Buscando responder o objetivo proposto neste estudo, realizamos uma pesquisa de abordagem qualitativa. Trata-se de um estudo de campo de natureza exploratória baseado na ação pedagógica interventiva em EF escolar. Esta pesquisa foi desenvolvida na dinâmica da disciplina de Estágio supervisionado no EM do curso de formação de professores de EF da Universidade do Vale do Itajaí e, aprovada pelo Comitê de Ética da universidade, segundo o parecer $\mathrm{n}^{\mathrm{0}} 782.635$.

A pesquisa desenvolvida na disciplina de estágio foi realizada em uma escola de educação básica de ensino público e mantida pelo estado de Santa Catarina. As aulas de EF na escola eram desenvolvidas conforme o modelo tradicional (AYOUB, 2003), seu conteúdo central eram os esportes, principalmente o futebol e o voleibol.

O processo investigativo que se fundamentou numa proposta de intervenção em aulas de EF para o EM utilizou os dados provenientes dos documentos e sistemáticas propostas pela 
disciplina de estágio curricular, sendo eles plano de ensino, planos de aulas e relatórios de campo elaborados semanalmente por dois estudantes-estagiários. As aulas aconteceram ao longo de 11 semanas, tinham duração presencial de $45 \mathrm{~min}$ e após cada um destes encontros eram propostas atividades e/ou momentos reflexivos e de debates através das redes sociais.

O plano de ensino se tornou o documento norteador da proposta, já que nele foram definidos os objetivos de aprendizagem a serem atingidos. Contudo, devido à característica principal da abordagem de aulas abertas, os conteúdos e estratégias de ensino eram estabelecidos pelos alunos e reestruturados nos espaços de diálogo e debates coletivos.

Após a apresentação da proposta aos alunos, a primeira ação foi definir juntamente com os estudantes os conteúdos a serem trabalhados e a estratégia para estas aprendizagens. Nesta roda de diálogos os alunos expuseram suas vontades e anseios, surgindo diferentes possibilidades de temas. Através da mediação do professor ficou definido que os jogos seriam o conteúdo central das aulas, priorizados nas temáticas de competição e cooperação. A segunda decisão tomada foi a utilização de uma gincana como estratégia de ensino. De forma coletiva foram sendo definidas, ao longo das aulas, quais e quantas atividades seriam realizadas, os critérios de pontuação, a divisão das equipes, entre outras decisões. Estas discussões aconteceram nas primeiras aulas e através das redes sociais.

Neste movimento, as aulas foram sendo pensadas a cada semana. No momento inicial de cada encontro eram relembradas as decisões e acordos já estabelecidos, e nos momentos finais e principalmente nas redes sociais eram estabelecidas novas ações. Este processo estimulou a elaboração semanal dos planos de aula e exigiu um registro contínuo e detalhado de todas as estratégias realizadas, diálogos e debates estabelecidos e análises interpretativas e conceituais sobre a prática pedagógica experenciada pelos professores e os impactos na postura e envolvimento dos alunos.

Desta forma, esses documentos (plano de ensino, plano de aula e relatórios de campo) foram utilizados como instrumentos de análise. Contudo, as reflexões constituídas nas rodas dialogadas, no início e no final das aulas, e das postagens dos alunos nas redes sociais foram significativas para o registro dos dados. Era solicitado aos alunos que refletissem sobre o desenvolvimento das aulas e de temáticas transversais como competição, ética, cidadania, entre outros. Os relatórios de campo foram elaborados observando aspectos como desenvolvimento pedagógico e metodológico, falas, participação e interesse, e os pressupostos inovadores.

Utilizamos como método de análise a organização temática ou categorial (BARDIN, 2002). Este método baseia-se em operações de desmembramento do texto em unidades, descobrindo núcleos de sentido que constituem a comunicação, para posterior reagrupamento em classes ou categorias. Na análise de conteúdo, Bardin (2002) aponta como pilares a fase da descrição ou preparação do material, a inferência ou dedução e a interpretação.

Dessa forma, os principais pontos da pré-análise são a leitura flutuante, a escolha dos depoimentos, a referenciação dos índices e elaboração dos indicadores e a preparação do material. Para isso, todos os depoimentos foram registrados e analisados na íntegra, não eliminando o caráter espontâneo dos textos. Na fase seguinte foi realizada a codificação, na qual foram feitos recortes em unidades de contexto e de registro. Na última fase os conteúdos recolhidos se constituíram em análises reflexivas, com observações individuais e gerais das falas dos alunos. Transcrições literais das falas foram incluídas no texto como forma de representar as unidades de contexto e de registro. $\mathrm{O}$ processo de organização resultou em três temáticas de análises: as redes sociais no processo educativo da Educação Física Escolar; a diversificação do conteúdo como estratégia pedagógica; e as aulas abertas como facilitador do processo ensino-aprendizagem. 


\section{Análises}

\section{Redes sociais no processo educativo da Educação Física}

As atividades da gincana foram elaboradas em conjunto entre professor e alunos. Em alguns casos o professor sugeria a atividade e os alunos definiam as regras, formas de pontuação e critérios para participação. Entretanto, a mediação do professor influenciou para que as tomadas de decisão dos alunos cumprissem com os objetivos do plano de ensino.

Como o tempo das aulas é reduzido, duas horas/aulas por semana, nem sempre há tempo suficiente para esse espaço de discussão. Como estratégia foi proposto o uso das redes sociais como espaço de discussão e de realização de tarefas relacionadas à gincana. A Figura 1 coloca a expectativa inicial e os potenciais observados na utilização das redes sociais.

Figura 1 - Expectativas inicias e potenciais observadas na utilização das redes sociais

\begin{tabular}{|l|l|}
\hline Expectativas iniciais & Potenciais observados \\
\hline Espaço de discussão & Espaço de discussão \\
Realização de tarefas & Realização de tarefas \\
& Espaço de avaliação (professor) \\
& Espaço de autoavaliação (aluno) \\
& Preservação do conteúdo \\
\hline
\end{tabular}

Fonte: Elaborada pelos autores, 2016.

As expectativas iniciais revelaram-se reducionistas. A ideia geral, que era fomentar discussões, foi alcançada. Num período de 10 semanas foram mais de 40 postagens de temáticas ligadas às aulas. Nestas postagens mais de $90 \%$ dos alunos visualizaram a informação e pelo menos $70 \%$ deles participaram ativamente da discussão, dando opiniões e sugestões sobre o tema. Numa das discussões um aluno coloca que "[...] foi empolgante estar presente em todos os momentos, aprender novas coisas [...]". Na ocasião o aluno fazia uma reflexão da participação dele na gincana e o fato de poder escrever sobre isso fez com que ele se sentisse presente em todos os momentos da aula.

A rede social também é útil e eficaz como espaço de realização de tarefas. Quando as atividades eram propostas, como a pesquisa de determinado assunto, todos os alunos cumpriam com o proposto.

A avaliação foi outra categoria que se revelou pedagogicamente importante. Na fala dos alunos o professor é capaz de identificar o entendimento sobre o assunto trabalhado, bem como o poder de crítica e reflexão. Numa das aulas práticas foi levantada a questão da competição dentro do processo escolar. Uma aluna apresentou a seguinte visão: “[...] tendo em mente que é importante ganharmos, mas mais importante ainda saber que demos o máximo pra chegar aonde chegamos [...]”. Claramente há uma valorização de todo processo competitivo e não apenas no resultado.

Ainda a ferramenta é útil, pois permite que o aluno se autoavalie. Reflete sobre o seu desenvolvimento e amplia a discussão questionando valores e atitudes. "[...] Desde o começo estamos vendo o quão importante que é a união, precisamos um dos outros pra poder chegar longe, estamos dando o máximo pra chegar o mais próximo da vitória, e chegar lá sabendo que não trapaceamos em momento nenhum [...]".

Uma categoria importante observada na utilização da rede social foi a preservação do conteúdo. Como as tarefas da gincana foram vinculadas à internet (trabalhos de pesquisa, curiosidades sobre o esporte, desafios de lógica), houve uma mobilização entorno da EF. A problematização e as discussões geraram um canal de comunicação agradável e confortável para 
o adolescente, permitindo autorreflexão. A aluna faz a seguinte consideração: "a gincana esta acontecendo de uma forma legal e interativa, assim a gente acaba aprendendo a se perceber".

É possível, portanto, considerar a utilização das redes sociais como estratégia inovadora na EF escolar. Ressalta-se a ampliação do binômio espaço-tempo destinado à EF; a atribuição de significado aos conteúdos trabalhados nas aulas; a preservação do conteúdo; e o fomento à problematização e discussão.

\section{A diversificação do conteúdo como estratégia pedagógica}

A primeira necessidade atribuída ao planejamento das aulas foi a diversificação do conteúdo; e a gincana mostrou-se útil por considerar diversos elementos da cultura corporal de movimento. Dentro da perspectiva aberta a gincana também permite a organização conjunta das regras, procedimentos e até mesmo a escolha das atividades. Este fato logo no início conferiu aos estudantes uma noção corresponsável do processo. Os aspectos gerenciais de uma gincana, como criar equipe, dar nome às equipes, grito de guerra, entre outros, aumentaram a identidade do grupo. Os alunos elegeram trabalhar com jogos e brincadeiras. A organização, ligada aos jogos competitivos e cooperativos, gerou categorias educacionais, conforme a Figura 2.

Figura 2 - Categorias educacionais em função da diversificação do conteúdo (gincana)

\begin{tabular}{|c|c|}
\hline las $\quad$ Com relação à participação nas au- & $\begin{array}{c}\text { Com relação às discussões ligadas } \\
\text { aos valores }\end{array}$ \\
\hline Motivação para aula & Competição/Cooperação \\
Ausência de evasão & Interaçâo social \\
& Valores (ética, respeito, amizade) \\
\hline
\end{tabular}

Fonte: Elaborada pelos autores, 2016.

Houve uma mobilização dos alunos em prol do projeto de construir e jogar a gincana. Ao que parece, aquilo que eles "escolhem" atende mais aos anseios dos adolescentes e os motiva para as aulas. A responsabilidade em construir algo e ser responsável pelo gerenciamento das atividades gerou motivação. Já na segunda aula, todos os alunos passaram a participar e um dos comentários chama atenção: "[...] observamos que os alunos estão mais participativos [...], o importante todos terem 'trabalhado' em grupo [...]".

A motivação naturalmente implicou na diminuição da evasão das aulas. Umas das estratégias, sugerida pelos próprios alunos, foi uma atividade chamada o resgate do colega. A prova consistia em convencer seus colegas a participarem da gincana e entrarem para suas equipes. No final do processo um dos resgatados faz a seguinte reflexão: "[...] a gincana é legal para o aprendizado, ela mexe com nossas emoções e nos proporciona compartilhar nosso jeito de ser, nossa cultura, nossa humanidade [...]". As diferentes atividades fizeram com que este adolescente, que por muitas vezes foi excluído das aulas, pudesse se sentir pertencente à aula e capaz de compartilhar o seu jeito "único" de ser.

Com relação aos valores, a discussão competição e cooperação esteve presente em todos os momentos das aulas. Na visão dos alunos a competição representa um elemento motivacional. Diante dos problemas apresentados pela competição foi possível discutir ética no processo competitivo, valores e atitudes. Um dos alunos faz a seguinte reflexão: "[...] estamos todos se empenhando para ganhar, quem sabe, o primeiro lugar, [...] mas o mais importante é competir com esperança e lealdade [...]". Este tipo de reflexão só foi possível mediante a provocação do professor e da discussão na rede social. Mesmo que em muitos momentos os alunos apresentassem atitudes diferentes do discurso, a fala implica numa maior tomada de cons- 
ciência, implica em autocrítica e expõe os alunos ao julgamento social entre aquilo que eles falam e fazem.

Numa das aulas a tarefa era: em duplas, de mãos dadas e com a mão de fora fechada. Foi sugerido que os alunos guardassem na mão fechada algum segredo, ou algo muito importante para eles, como seus sonhos. O professor problematizou dizendo que o objetivo da atividade era abrir o maior número de mãos possíveis, sem largar a mão da sua dupla. Venceria a atividade aqueles que abrissem o maior número de mãos.

Com o desenvolvimento da atividade os adolescentes apresentaram 3 tipos de comportamentos: (1) aqueles que tentaram abrir a mão do colega (estes usaram os pés, a força, morderam, tentaram persuadir os colegas); (2) os que não perceberam nenhuma possibilidade de abrir as mãos, pois estavam com uma mão presa ao colega e a outra fechada; e (3) os que abriram mão dos seus sonhos, abrindo suas próprias mãos, em prol de revelar o sonho do outro. Este é um exemplo de atividade que apresenta um campo fértil para discussão e reflexão. Neste exemplo o professor tratou de temáticas como preservação da vida e dos sonhos e sobre violência. Três aspectos foram levantados pelos alunos: "Muitas vezes não valia a pena vencer só para 'destruir' o sonho do colega"; "Na tentativa de revelar o sonho perceberam que haviam sonhos em comum"; "Na ausência de sonho a atitude pessoal pode ser destrutiva".

Em oposição à noção que a competição é naturalmente excludente, nossos resultados mostram que ela foi importante para aumentar os valores cooperativos. Segundo a fala de um dos alunos: "aprendemos a interagir em grupo, com união, um dependendo do outro, com muita força e confiança [...]". Falam também que competir é importante "[...] para assim, levar boas influências ao longo da vida". Portanto, valores e atitudes também foram evidenciados a partir da atitude cooperativa; e um aluno finaliza: "as amizades se tornam mais sólidas depois da gincana e descobrimos habilidades que não conhecemos".

\section{As aulas abertas como facilitador do processo de ensino-aprendizagem}

A concepção pedagógica que embasou este trabalho foi a das aulas abertas. Na primeira aula, quando proposto, os alunos reagiram com desconfiança, pouco encorajamento e medo de errar. Os alunos também confundiram o conceito de aberto com livre. Para isso, uma breve explicação teórica sobre aulas abertas foi ministrada. Como estratégia foi enfatizada a necessidade de construção em conjunto da gincana. Foi reforçada a possibilidade de escolha das atividades, a forma de pontuação, equipes e o gerenciamento da gincana. Apesar disso, nas primeiras aulas não havia ação comunicativa.

Duas estratégias mudaram o paradigma das aulas, a inclusão da rede social como espaço e discussão e a formação das equipes. No primeiro caso, o ambiente virtual se mostrou mais encorajador para os alunos opinarem e as discussões na rede social impulsionaram a comunicação também em sala de aula. A formação das equipes gerou identidade coletiva, pois tiveram que escolher os nomes das equipes e criar um grito de guerra.

A partir da $2^{\mathrm{a}}$ aula foi possível observar avanços importantes como: maior participação na construção da gincana, melhora na ação comunicativa, reflexão e motivação para as aulas. Todas estas categorias estiveram ligadas ao aumento da autonomia dos alunos aumentando a participação. Algumas falas exemplificam as análises: "A gincana está sendo legal, está sendo diferente, pois estamos saindo um pouco da rotina"; "Desde o começo estamos vendo o quão importante é a união"; "Precisamos um dos outros para poder chegar longe"; "Esperamos ansiosamente a próxima partida". 


\section{Discussão}

\section{As redes sociais no processo educativo da Educação Física}

A consolidação das mídias e da tecnologia evidencia o impacto cultural das redes sociais na vida das pessoas (JENKIS, 2008). Este cenário, por vezes controverso, nos coloca diante de uma potencial ferramenta educacional inovadora. Isso porque, ao que parece, as mídias têm possibilitado uma maior interação e autonomia dos receptores/consumidores na escolha, veiculação e até produção dos conteúdos e esse fato tem dinamizado a vida dos adolescentes brasileiros (BETTI; MENDES; PIRES, 2009).

Cenários como este, onde há proliferação do acesso aos meios de informação e comunicação, considerando a função da escola em favorecer a apropriação da cultura, deveriam promover intensamente a análise e compreensão deste fenômeno (BETTI, 2006). A Educação Física (EF), por consequência, deveria fazer o mesmo. No esporte é notória a impregnação da mídia no esporte e vice-versa (BETTI, 1998).

Esse sentido impregnado, invadido e penetrado da relação conteúdo e mídia reflete as características das nossas análises. Os conteúdos trabalhados na gincana receberam ampliação de significado, na medida em que foram discutidos, avaliados e autocriticados nas redes sociais. Ainda tornou-se preservado. Observa-se que esse processo de significação das mídias influencia a sociedade como um todo, reorganizando a cultura corporal de movimento e evidenciando novas formas de organização e valores (BETTI, 2009a).

As tecnologias, ao contrário da monotonia e falta de significado da escola tradicional, modificam a forma e a maneira dos alunos perceberem o mundo. $\mathrm{O}$ conteúdo, por ser mais atrativo e dinâmico, transforma as formas de se expressar (BELLONI, 2001). Estas transformações têm impactado na relação que os adolescentes apresentam com conteúdos tradicionais da EF, como o esporte, gerando em muitos casos resistência e negação.

A resistência a esses conteúdos tradicionais pode ser considerada um problema nos currículos da EF. Isso parece evidenciar a dificuldade que passa a EF em realizar uma atualização pedagógica. É nesse sentido que alguns autores consideram que as propostas curriculares da área possuem impactos inovadores questionáveis (ANDRADE, 2013), pois não possibilitam que os alunos reconheçam as manifestações corporais que problematizam a vida, bem como as fontes de referências que fornecem os significados. Nossos dados apontam que a utilização das redes sociais proporciona um ambiente mais "familiar e confortável" para que o adolescente possa se manifestar, discutir, pesquisar e ampliar os significados dos conteúdos.

\section{A diversificação do conteúdo como estratégia pedagógica}

Atualmente, o esporte é o veículo mais utilizado como forma de difusão do movimento corporal na educação básica. Mais do que isto, somente algumas modalidades esportivas como o futebol, basquetebol e voleibol fazem parte do conteúdo das aulas de EF. Outras manifestações raramente são difundidas nos programas (FERREIRA; GRAEBNER; MATIAS, 2014). Dessa problemática emerge o reducionismo da área. Sentidos como o expressivo, o criativo e o comunicativo, que se manifestam em outras atividades de movimento, não são explorados como conteúdo escolar. Isso porque o sentido esportivo passou a ser o conteúdo hegemônico da EF (KUNZ, 2004b).

Nossos resultados evidenciam essa carência educacional e o vácuo que a construção histórica da EF impôs aos alunos do EM. As categorias educacionais e pedagógicas evidenciadas pelos alunos diante da diversificação do conteúdo apontam que os adolescentes anseiam por novidades. Isto implica em mais motivação e, consequentemente, ausência da evasão das 
aulas. Kunz (2004a) evidencia a necessidade de mudanças na maneira de enfrentar a primazia da ação na EF e salienta a importância da dimensão reflexiva.

A introdução de novas formas de atividades e organização do currículo tem sido defendida por diversos autores. E alguns enfatizam a necessidade da ação comunicativa, em que a reflexão surge do interjogo da relação educador e educando, problematizando não só a ação, mas a práxis social. O trabalho de Santos e Silva (2011) reflete aspectos propostos teoricamente. As aulas foram planejadas com conhecimentos que tivessem sentido e significado a partir da realidade em que os alunos se encontravam. O resultado desse processo foi naturalmente a diversificação dos conteúdos, visto que as necessidades dos alunos, bem como a dinâmica de suas realidades apresentam características diferentes.

O conceito de diversificação não está apenas na escolha de diferentes atividades, acontece na medida em que os alunos, por exemplo, percebem a dança como uma linguagem social que permite a transmissão de sentimentos e emoções da afetividade vivida; que são confrontados com a diversidade de jogos; que a dimensão histórica, o trabalho, os costumes sejam considerados para produzir uma dimensão complexa nas aulas. Os códigos, sentidos e significados passam a ter significado a partir da realidade do aluno e da sociedade que o produz (TAFFAREL, 2012).

Nossos resultados mostram que na diversificação a relação competitiva apresentou diferentes perspectivas e problematizou a cooperação, a interação social e valores como ética, respeito e amizade. Isto só é possível na medida em que as aulas superam a dimensão puramente procedimental. Observa-se que diferentes experiências práticas problematizadas e discutidas teoricamente assumem novas dimensões e significados (KRAVCHYCHYN; OLIVEIRA; CARDOSO, 2008).

Com relação às estratégias pedagógicas, nossos resultados evidenciam que para o professor de EF agregar valores e significados aos conteúdos é preciso atribuir valores e significados aos alunos e àquilo que eles produzem. Faz-se necessário unir o prazer que a disciplina exerce e a reflexão crítica sobre aquilo que se vivencia nas aulas. Assim, evidencia-se o porquê e o quão importante é cada atividade. Elimina-se, neste caso, o "fazer pelo fazer", gera-se significado às aulas (MOREIRA; SIMÕES; MARTINS, 2010).

\section{As aulas abertas como facilitador do processo de ensino-aprendizagem}

A proposta pedagógica que embasou este estudo caracteriza-se pela participação dos alunos nas decisões referentes aos objetivos, seleção dos conteúdos, metodologia e avaliação. A proposta de aulas abertas (HILDEBRANDT; LAGING, 1986) coloca os alunos na condição de estabelecer relações complexas de decisão. O grau de abertura depende do grau de decisão e possibilidades de codecisão.

Desde o planejamento pressupõe-se a concepção aberta, neste caso, os alunos decidiram quais, como e de que forma as aulas seriam desenvolvidas. A decisão mantém o caráter individual de escolha e implica em procurar uma ligação do aprender escolar com a vida e experiência dos alunos. Considera-se as necessidades e interesses, medos e aflições dos alunos e amplia o desenvolvimento na discussão social. A relação entre movimento, percepção e realização possibilita aos alunos a participação em todas as etapas do processo de ensinoaprendizagem (HILDEBRANDT, 2005; HILDEBRANDT; LAGING, 1986).

Diferente das aulas fechadas, a perspectiva aberta propõe a orientação do aluno através da problematização e da comunicação (HILDEBRANDT, 2005). O professor admite o protagonismo do aluno; entende que a pluralidade das manifestações, comportamentos e atitudes é o cerne para gerar discussão, reflexão e significado. Lira Neto (2008) coloca que uma das principais preocupações no ensino da EF baseado nas aulas abertas é considerar o interesse do 
aluno e possibilitar o seu papel ativo na relação com os conteúdos, permitindo ao aluno a elaboração da subjetividade na sua relação com os movimentos.

Nossos resultados corroboram com a literatura quando é percebido que o ensino numa concepção de aulas abertas estimula o desenvolvimento da autonomia. Mais que isso, a autonomia impulsionou aspectos como maior participação nas aulas e melhora na ação comunicativa. Segundo Freire e Scaglia (2003), o professor precisa estar preparado para o desenvolvimento da autonomia, pois para se tornar autônomo é preciso trilhar caminhos de encorajamentos (FREIRE, 2004).

\section{Considerações finais}

A proposta aponta que a utilização das redes sociais amplia o binômio espaço-tempo destinado à Educação Física e favorece a apropriação e a manutenção do conhecimento permitindo que os alunos permaneçam refletindo sobre as aulas. A educação pela descoberta, pesquisa, discussão e problematização revela-se campo útil e confortável para o aluno tomar decisões conscientes, com significado e com alto grau de valorização pessoal.

A diversificação do conteúdo gerou categorias pedagógicas importantes como motivação para as aulas e ausência de evasão. Permitiu também que categorias educacionais fossem observadas, como a competição/cooperação, a interação social e a discussão de valores. A diversificação como conceito, neste trabalho implica, além das diferentes atividades, em produzir uma dimensão mais complexa nas aulas.

Por fim, a concepção pedagógica que embasou este estudo mostra-se eficaz e inovadora na EF no ensino médio. Ao considerar o aluno como coagente das aulas, incluindo-o nas decisões pedagógicas e metodológicas, foi observada maior participação, motivação e fomento à ação comunicativa, categorias fruto da construção autônoma do aluno.

\section{Referências}

ANDRADE, A. Pós-graduação em educação física, inovação e prática pedagógica: reflexões iniciais. Filosofia e Educação (on-line), Campinas, SP, v. 5, n. 2, p. 29-42, 2013.

AYOUB, E. Educação física escolar: compromisso e desafios. Motus Corporis, Rio de Janeiro, v.10, n. 1, p. 106-117, 2003.

BARDIN, L. Análise de conteúdo. Lisboa: Edições 70, 2002.

BELLONI, M. L. O que é Mídia-Educação. Campinas, SP: Autores Associados, 2001.

BETTI, M. A janela de vidro: esporte, televisão e educação física. Campinas, SP: Papirus, 1998.

BETTI, M. A pedagogização dos conteúdos da Educação Física: tradição e renovação. São Paulo: Hucitec, 2009a.

BETTI, M. Educação Física Escolar: ensino e pesquisa-ação. Ijuí, RS: Unijuí, 2009b.

BETTI, M. "Imagens em ação": uma pesquisa-ação sobre o uso de matérias televisivas em programas de educação física do ensino fundamental e médio. Movimento, São Paulo, v. 12, n. 02, p. 95-120, Porto Alegre, 2006. 
BETTI, M.; MENDES, D. S.; PIRES, G. L. Imagem e ação: as mídias e a educação física escolar. In: BETTI, M. Educação Física Escolar: ensino e pesquisa-ação. Ijuí, RS: Unijuí, 2009.

BRANDOLIN, F.; KOSLINSKI, M.; SOARES, A. J. G. A percepção dos alunos sobre a educação física no ensino médio. Journal of Physical Education, v. 26, n. 4, p. 601-610, 2015.

BRASIL. Ministério da Educação. Parâmetros curriculares nacionais: linguagens, códigos e suas tecnologias. Brasília: Secretaria da Educação Média e Tecnologia, parte 2, 2000. p. 71. Disponível em: <http://portal.mec.gov.br/seb/arquivos/pdf/linguagens02.pdf>. Acesso em: 3 out. 2016.

DAOLIO, J. A ordem e a (des)ordem na educação física brasileira. Revista Brasileira de Ciências do Esporte, Brasília, v. 25, n. 1, p. 115-127, set. 2003.

DARIDO, S. C. Educação física na escola: questões e reflexões. Rio de Janeiro: Guanabara Koogan, 2003.

FERREIRA, M. L. dos S.; GRAEBNER, L.; MATIAS, T. S. Percepção de alunos sobre as aulas de educação física no ensino médio. Pensar a Prática, Goiânia, v. 17, n. 3, p. 734-750, jul./set. 2014.

FREIRE, P. Pedagogia da autonomia: saberes necessários à prática educativa. São Paulo: Paz e Terra, 2004.

FREIRE, P. Pedagogia do Oprimido. 17. ed. Rio de Janeiro: Paz e Terra, 1987.

FREIRE, J. B.; SCAGLIA, A. J. Educação como prática corporal. São Paulo: Scipione, 2003.

GARIGLIO, J. A. Os objetos-condições do trabalho docente de professores de Educação Física de uma escola profissionalizante. Currículo sem fronteiras, v. 15, n. 1, p. 195-230, jan./abr. 2015.

HILDEBRANDT, R. Textos pedagógicos sobre o ensino da Educação Física. 3. ed. Ijuí, RS: Unijuí, 2005.

HILDEBRANDT, R.; LAGING, R. Concepções abertas ao ensino da educação física. Rio de Janeiro: Livro Técnico, 1986.

JENKIS, H. Cultura da convergência. São Paulo: Aleph, 2008.

KRAVCHYCHYN, C.; OLIVEIRA, A. B.; CARDOSO, S. V. Implantação de uma proposta de sistematização e desenvolvimento da Educação Física do Ensino Médio. Movimento, Porto Alegre, v. 14, n. 2, p. 39-62, maio/ago. 2008.

KUNZ, E. Educação Física: ensino e mudanças. 3. ed. Ijuí, RS: Ed. Unijuí, 2004a.

KUNZ, E. Transformação didático-pedagógica do esporte. 6. ed. Ijuí, RS: Ed. Unijuí, 2004b. 
LIRA NETO, J. F. Relações entre a proposta das concepções abertas no ensino da educação física e o método Paulo Freire. Revista da Faculdade de Educação Física da UNICAMP Conexões, Campinas, São Paulo, v. 6, n. 2, p. 62-81, 2008.

MOREIRA, W.; SIMÕES, R.; MARTINS, I. C. Aulas de Educação Física no Ensino Médio. Campinas, SP: Editora Papirus, 2010.

OLIVEIRA, A. A. B. Metodologias emergentes no ensino da Educação Física. Revista da Educação Física/ UEM, Maringá, Paraná, v. 8, n. 1, p. 21-27,1997.

SANTOS, M. A. L.; SILVA, L. M. Cultura e práticas corporais: conteúdos e metodologias para o componente curricular Educação Física. Scientia Plena, Sergipe, v. 7, n. 8, p. 1-9, 2011.

TAFFAREL, C. N. Z. Formação de Professores de Educação Física: Diretrizes para a formação unificada. Revista Kinesis CEFD/UFSM, Santa Maria, RS, v. 30, n. 1, p. 95-133, 2012.

Recebido em: 15/10/2017

Revisado em: 01/11/2017

Aprovado em: 17/11/2017

Endereço para correspondência:

thiagosousamatias@gmail.com

Thiago Sousa Matias

Universidade Federal de Santa Catarina, Departamento de Educação Física do Centro de Desportos

R. Dep. Antônio Edu Vieira - Pantanal

88036-020 - Florianópolis - SC - Brasil 